http://jmscr.igmpublication.org/home/

ISSN (e)-2347-176x ISSN (p) 2455-0450

crossref DOI: https://dx.doi.org/10.18535/jmscr/v7i7.103

Journal Of Medical Science And Clinical Research

IGM Publication

An official Publication of IGM Publication

\title{
The Effect of Occlusal Disharmony on Temporomandibular Dysfunction
}

\author{
Authors \\ Dr Muhammad Waly Ahad ${ }^{1}$, Dr Rubaba Ahmed², Dr Khurshida Tanzir³, \\ Dr Alia Sultana ${ }^{4}$ \\ ${ }^{1}$ Associate Professor (Current Charge), Department of Dentistry, M Abdur Rahim Medical College, \\ Dinajpur \\ ${ }^{2}$ Associate Professor, Department of Prosthodontics, University Dental College \& Hospital, Dhaka \\ ${ }^{3}$ Associate Professor \& Head, Department of Prosthodontics, City Dental College, Dhaka \\ ${ }^{4}$ Associate Professor \& Chairman, Department of Prosthodontics, Faculty of Dentistry, BSMMU, Dhaka \\ Corresponding Author \\ Dr Muhammad Waly Ahad
}

\begin{abstract}
Introduction: Over the years, occlusion disharmony were accepted as one of the major causes of functional disorders of the temporomandibular joint (TMJ).

Objective: The goal of this research is to examine the effects of Occlusal Disharmony on TMJ.

Methodology: This observational study was conducted at Department of Prosthodontics, Faculty of Dentistry, Bangabandhu Sheikh Mujib Medical University, Shahbagh, Dhaka, Bangladesh from January 2006 to December 2007 among 150 patients. Data were collected on the basis of the clinical and radiological record and associated changes on some specific parameters (mentioned in methodology). Collected data in terms of different parameters were shown in tabular form and statistical analysis was done to observe the statistical significance.
\end{abstract}

Results: Among the group I patients $20.0 \%$ had Class I (Normal) molar relation, Highest $40.0 \%$ had class II molar relation and $20.0 \%$ had no molar relation and class III molar relationship. Among the group I patients, highest $40.0 \%$ had $1-2$ and $>5 \mathrm{~mm}$ over bite, $20.0 \%$ had edge to edge relation of anterior teeth and none had 3-5 $\mathrm{mm}$ (normal) relation. Among the group II patients $22.4 \%$ had edge to edge relation, none was in found 1-2 mm, 59.7\% had 3-5 $\mathrm{mm}$ and $17.9 \%$ had $>5 \mathrm{~mm}$. Among the group III patients $14.3 \%$ had edge to edge relation, $1-2 \mathrm{~mm}$ and 3-5 $\mathrm{mm}$ and $57.1 \% \mathrm{had}>5 \mathrm{~mm}$.

Conclusion: We can conclude from our result that that in the TMJ temporomandibular dysfunction (TMD), occlusal disharmonies were significant

Keywords: Temporomandibular joint dysfunction, Occlusal disharmonies, Masticatory system.

\section{Introduction}

The term occlusion is characterized in the word reference as the demonstration of conclusion or being shut. Shockingly, in dentistry the term frequently hints a static, morphologic tooth contact relationship. In any case, the term ought to have in its definition the idea of a multifactorial utilitarian connection between the teeth and different parts of the masticatory system just as with different territories of the head and neck that legitimately or in a roundabout way relate work, para capacity, or brokenness of the masticatory system. ${ }^{[1]}$ 
The alignment and occlusion of the dentition are critical in masticatory function. The essential exercises of biting, gulping, and talking depend enormously not just on the situation of teeth in the dental arches yet in addition on the relationship of the restricting teeth when they are acquired to occlusion. Tooth positions are resolved not by some coincidence, however by various controlling factors, for example, arch width and tooth estimate. Encompassing delicate tissue power additionally meddle the tooth position. ${ }^{[2]}$

The TMJ is a standout amongst the most unpredictable joints in the human body and is the region wherein the mandible articulates with the cranium. It accommodates hinging movement in one plane and thusly can be viewed as a ginglymoid joint. At same time it additionally accommodates gliding movements, which orders it as an arthrodial joint.

For the dental specialist endeavoring to deal with a TMD understanding, it is basic to welcome the real causes that might be related with the condition in light of the fact that legitimate ID of the right factor is basic for choosing appropriate and viable treatment. An audit of the logical writing uncovers the five central point related with TMD: (1) Occlusal Condition, (2) Trauma, (3) Emotional Stress (4) Deep Pain Input, and (5) Parafuntional Activity (Jeffrey P. Okeson 2003, p. 162). Truth be told, the significance of any of these elements differs incredibly from patient to quiet. Impediment is most significant, as it is the novel focal point of dentistry. ${ }^{[3][4][5]}$

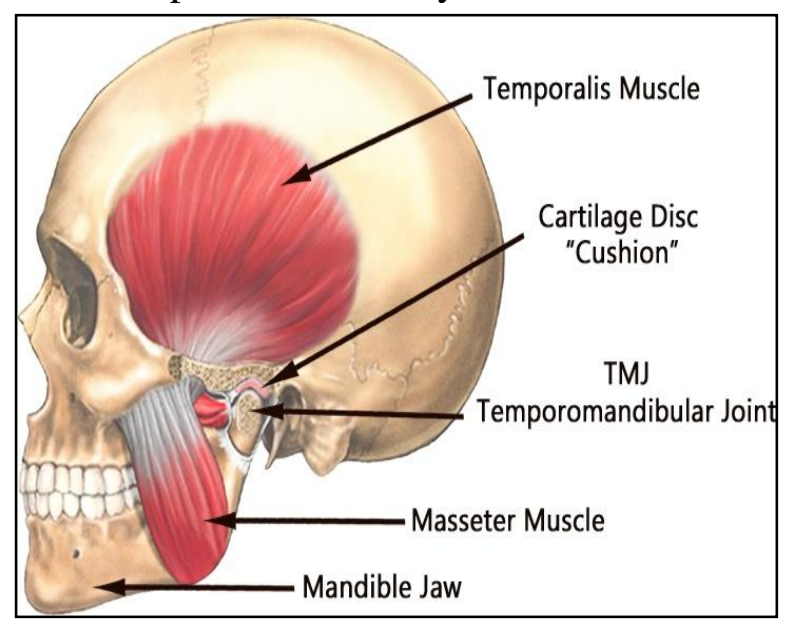

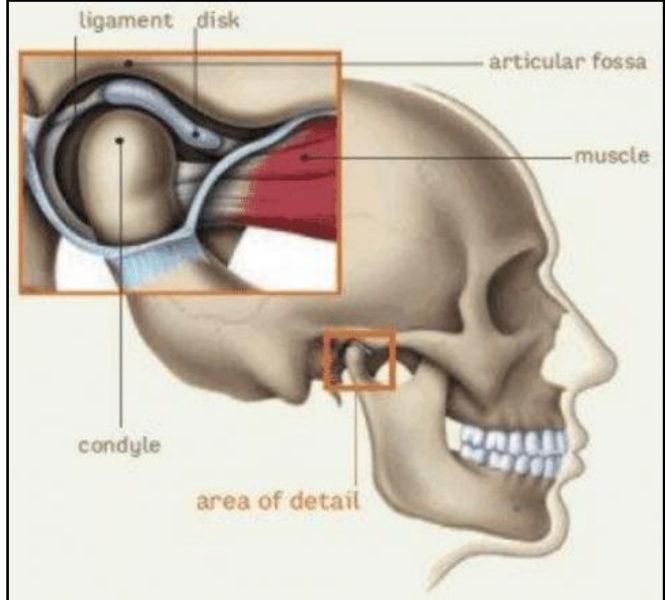

Figure 1a and 1b: Temporomandibular Dysfunction (TMD)

In this study our main objective is to evaluate the Effect of Occlusal Disharmony on Temporomandibular dysfunction.

\section{Objective}

\section{General Objective}

$>$ To evaluate the effects of Occlusal Disharmony on TMD.

\section{Specific Objective}

$>$ To identify the patients in groups by molar relations

$>$ To identify the patients in group by over bite

$>$ To identify the patients in groups by over jet

\section{Methodology}

\section{Study type}

$>$ The study was an observational study.

\section{Place and period of study}

$>$ The study was conducted in the Department of Prosthodontics, Faculty of Dentistry, Bangabandhu Sheikh Mujib Medical University, Shahbagh, Dhaka, Bangladesh from January 2006 to December 2007.

\section{Study Population}

$>$ Study population was selected on the basis of inclusion and exclusion criteria.

\section{Sample Size and sampling technique}

$>$ During the study period 150 samples were available which were included in this study. Sample was selected purposively. 


\section{Grouping of the subjects}

$>$ In this study total number of patients were150, Total patients had been divided into three groups (Group I, Group II \& Group III). In group I only the patients associated with Masticatory muscle pain (MMP) were included. In group II the patients with Masticatory muscle pain (MMP) with temporomandibular joint dysfunction (TMD) were included and in group III patients were selected who were suffering from pain only associated with temporomandibular joint dysfunction (TMD). Data were collected on the basis of the clinical and radiological record and associated changes on some specific parameters. Collected data in terms of different parameters were shown in tabular form and statistical analysis was done to observe the statistical significance.

\section{Selection Criteria}

\begin{tabular}{|l|l|}
\hline \multirow{4}{*}{$\begin{array}{l}\text { Inclusion } \\
\text { criteria }\end{array}$} & $\begin{array}{l}\text { Patients with missing teeth in the } \\
\text { premolar, molar region and anterior } \\
\text { teeth. }\end{array}$ \\
\cline { 2 - 2 } & With premature contact. \\
\cline { 2 - 2 } & Faulty restoration \\
\cline { 2 - 2 } & $\begin{array}{l}\text { Patients with missing teeth in the } \\
\text { premolar, molar region and anterior } \\
\text { teeth. }\end{array}$ \\
\hline \multirow{4}{*}{$\begin{array}{l}\text { Exclusion } \\
\text { criteria }\end{array}$} & Patients with ankylosis of the TMJ. \\
\cline { 2 - 2 } & Patients with the history of trauma. \\
\cline { 2 - 2 } & More than 65 years of age. \\
\cline { 2 - 2 } & Full mouth edentulous. \\
\hline
\end{tabular}

\section{Clinical and radiological evaluation}

$>$ Patients were examined clinically and radiographically (transcranial lateral oblique view and/or tomograph of TMJ and/or orthopantomgraph). A master cast and radiograph were preserved. Condyle position was identified by the radiological evaluation and occlusal derangement was find out from the clinical record as well as from the master cast.

\section{Radiographical Evaluation}

$>$ From the panaromic radiograph the screening of the condyles were done and recorded. By transcranial lateral oblique view the condyles and articular fossa are well studies and recorded the relation. From lateral view of the TMJs evaluation of joint structures was done. Bony changes and functional relationship of the joint also recorded.

\section{Data Collection and analysis}

$>$ Data were collected according to the predesigned structural data collection sheet on the basis of specific prefixed parameters. At first all of the relevant collected data were edited and complied on a master chart. Collected data were analyzed by using statistical package for social science (SPSS) after coding and scoring. Results were presented in bar diagrams.

\section{Results}

In table-1 indicates age appropriation of the patients it was clear that among the group I patients, most elevated rate $60.0 \%$ were $31-45$ years of age group and $26.67 \%$ were $\leq 30$ and $19.33 \%$ were $\geq 46$ age group. Among the group II patients, most astounding rate $50.0 \%$ were $\leq 30$ age group followed by $26.67 \%$ were $\geq 46$ years old group and $23.33 \%$ were $31-45$ years age group. While among the group III patients, most noteworthy rate $57.33 \%$ were $\geq 46$ years age group pursued by $28.0 \%$ were $\leq 30$ years of age group and $14.67 \%$ were $31-45$ years age group. The accompanying table is given beneath in detail:

Table-1: Age group distribution of the patients

\begin{tabular}{|l|c|c|c|}
\hline Group & $\begin{array}{c}\leq 30 \text { years } \\
\mathbf{\%}\end{array}$ & $\begin{array}{c}\mathbf{3 1 - 4 5} \text { years } \\
\mathbf{\%}\end{array}$ & $\mathbf{\geq 4 6}$ years, $\%$ \\
\hline Group I & $20.67 \%$ & $60 \%$ & $19.33 \%$ \\
\hline Group II & $50 \%$ & $23.33 \%$ & $26.67 \%$ \\
\hline Group III & $28 \%$ & $14.67 \%$ & $57.33 \%$ \\
\hline
\end{tabular}

*where, $\mathrm{n}=$ in group I = Masticatory muscle pain (MMP) group II =Masticatory muscle pain (MMP) with Temporomandibular joint dysfunction (TMD) and group III = Temporomandibular joint dysfunction (TMD) 
In figure-2, it indicates the sex dissemination among patients where It was discovered that among group I, $78.7 \%$ were female and $21.3 \%$ were male patients, among group II $28.9 \%$ was male and $71.1 \%$ was female patients and among group III $42.4 \%$ was male and $57.6 \%$ was female patients. Altogether $33.0 \%$ were male patients and $67.0 \%$ were female patients. The accompanying figure is given underneath in detail:

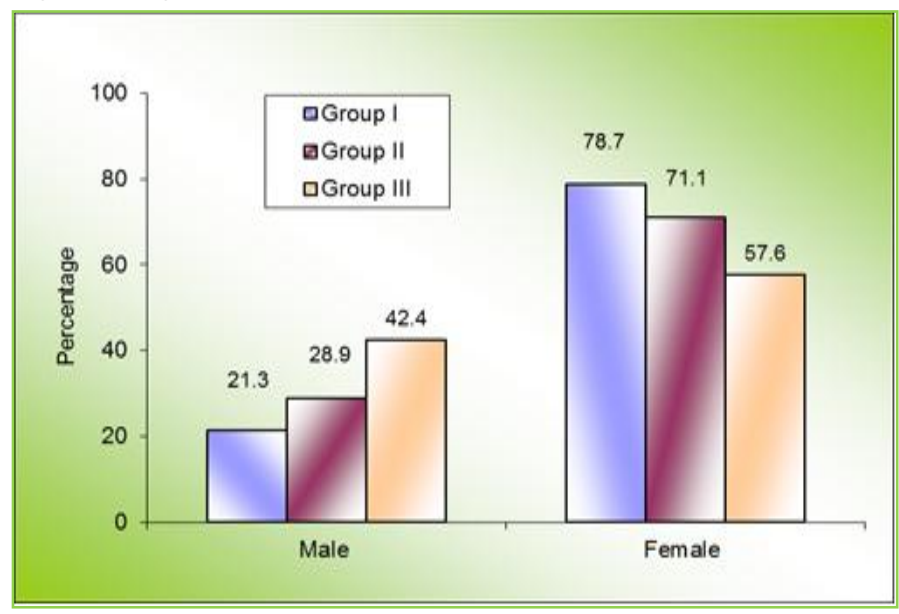

Figure-2: Sex distribution among patients

Figure 3 indicates occlusal condition of the patients; it was apparent that among the group I patients $20.0 \%$ had class I (normal) molar relation, highest $40.0 \%$ had class II molar relation and $20.0 \%$ had no molar relation and class III molar relationship. Among the group II patients $10.4 \%$ had no relation, $14.9 \%$ had class I, and $37.3 \%$ had class II and class III molar relations. Among the group III patients $42.9 \%$ had no molar relation, $3.6 \%$ was found in class II and I and $50.0 \%$ had class III molar relation.

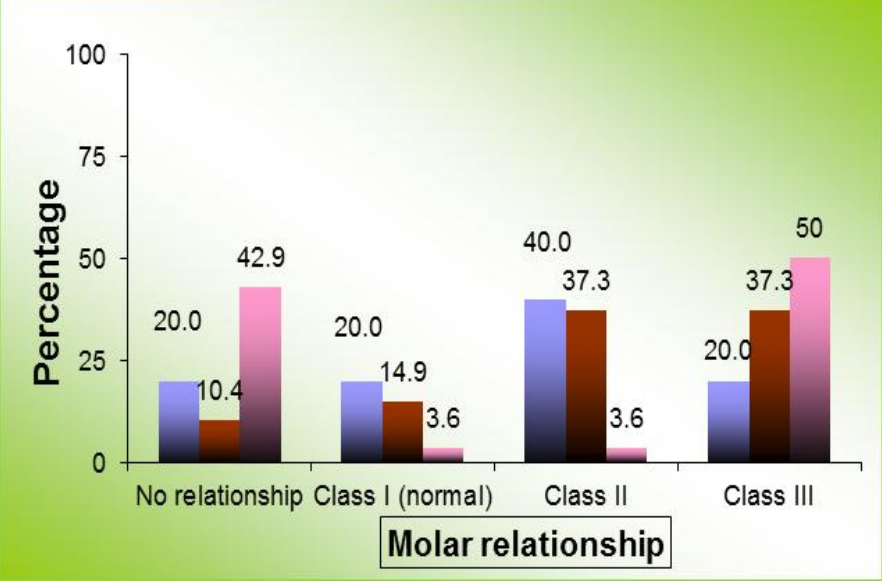

Figure 3: Dissemination of patients in groups by molar relation
In figure 4, among the group I patients, most elevated $40.0 \%$ had $1-2$ and $>5 \mathrm{~mm}$ over bite, $20.0 \%$ had edge to edge molar relation of anterior teeth and none had 3-5 mm (normal) previously mentioned molar relation. Among the group II patients $22.4 \%$ had edge to edge molar relation, none was in discovered 1-2 mm, 59.7\% had 3-5 $\mathrm{mm}$ and $17.9 \%$ had $>5 \mathrm{~mm}$. Among the group III patients $14.3 \%$ had edge to edge molar relation, 1$2 \mathrm{~mm}$ and $3-5 \mathrm{~mm}$ and $57.1 \%$ had $>5 \mathrm{~mm}$.

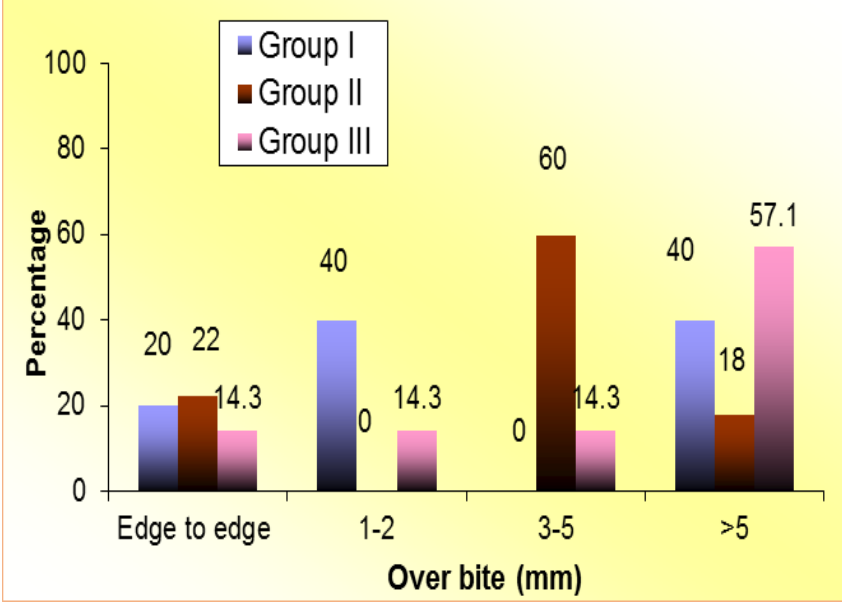

Figure 4: Dissemination of patients in groups by over bite

Accordingly, it was seen in Figure 5, among the group I patients, most astounding $60.0 \%$ had 1-2 $\mathrm{mm}$ over bite, $20.0 \%$ had edge to edge molar relation and $>5 \mathrm{~mm}$ over jet. Among the gathering II patients $28.4 \%$ had edge to edge molar relation, $13.4 \% 1-2 \mathrm{~mm}, 41.8 \%$ had $3-5 \mathrm{~mm}$ and $16.4 \%$ had $>5 \mathrm{~mm}$. Among the group III patients $28.6 \%$ had edge to edge molar relation, $14.3 \%$ had 1 $2 \mathrm{~mm}, 57.2 \%$ had $3-5 \mathrm{~mm}$ and none had $>5 \mathrm{~mm}$.

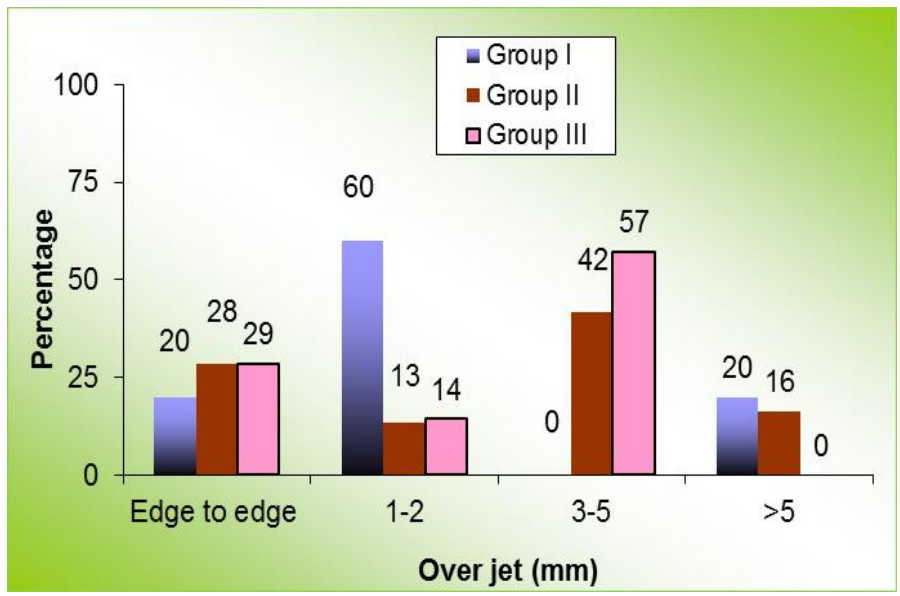

Figure 5: Dissemination of patients in groups by over jet 


\section{Discussion}

Occlusal analysis of the gatherings showed that every one of the 150 patients had different occlusal impedances in their circular segment of conclusion when condyles were situated completely in the most prevalent position inside the articular fossa. These impedances brought about condylar displacement, as envisioned on remedied tomograms amid maximum intercuspation.

The quantity of occlusal contacts in different mandibular position shifted, as it were, as did over jet (vertical overlap) and overbite (horizontal overlap). Among the group I patients none had normal 3-5 $\mathrm{mm}$ over bite, all patient had either edge to edge relation or $1-2 \mathrm{~mm}$ and $>5 \mathrm{~mm}$ over bite. Among the group II patients $59.7 \%$ had 3-5 $\mathrm{mm}$ (normal) and rest $40.3 \%$ had edge to edge relation, $1-2 \mathrm{~mm}$ and $>5 \mathrm{~mm}$ anterior relation. Among the group III patients $14.3 \%$ had $3-5 \mathrm{~mm}$ (normal) over bite while $85.7 \%$ had edge to edge relation, $1-2 \mathrm{~mm}$ and $>5 \mathrm{~mm}(57.1 \%)$ over jet. Altogether $44.0 \%$ had normal $3-5 \mathrm{~mm}$ over bite, $30.0 \%$ had $>5 \mathrm{~mm}, 20.0 \%$ had edge to edge relation because of loss of natural molar teeth and just $6.0 \%$ had $1-2 \mathrm{~mm}$ over bite. It is clear that over jet is related with TMD.

Likewise, it was seen among the group I patients none had typical 3-5 mm over jet, $60.0 \%$ had 1-2 $\mathrm{mm}$ over jet, $20.0 \%$ had edge to edge and $>5 \mathrm{~mm}$ over jet. Among the group II patients $41.8 \%$ had 3-5 mm (normal) over jet though $28.4 \%$ had edge to edge relation and $13.4 \%$ had $1-2 \mathrm{~mm}$ and $16.4 \%$ had $>5 \mathrm{~mm}$. Among the group III patients $57.1 \%$ had $3-5 \mathrm{~mm}$ normal over jet while $42.9 \%$ had edge to edge relation and $1-2 \mathrm{~mm}$ and none had $>5 \mathrm{~mm}$. Altogether $44.0 \%$ had normal 3-5 $\mathrm{mm}$ over nibble, $56.0 \%$ had edge to edge, $1-2 \mathrm{~mm}$ and $>5 \mathrm{~mm}$ over fly. It demonstrates the majority of the TMD understanding had got nonconforming over jet. One contributing factor to TMD that has been unequivocally bantered for a long time in the occlusal condition. Right off the bat in the advancement of this field, occlusion was viewed as the most significant contributing factor in TMD. In any case, more as of late numerous specialists contended that occlusal factors assume almost no effect in TMD. ${ }^{1}$ Another significant factor that help to balance out tooth alignment is occlusal contact, which avoids the expulsion or supereruption of teeth, in this way keeping up arch dependability. Each time the mandible is shut, the special occlusal-contact design reemphasizes and keeps up tooth position. Subsequently it ends up evident that the proximal and occlusal contacts are significant in keeping up tooth alignment and arch integrity. ${ }^{[6]}$

The progressions of occlusal parameters in the centric occlusion are normal for the patients with temporomandibular joint disorders. In any case, not just occlusal and articulatory surfaces assume a significant job in the human articulatory system, yet in addition masticatory muscles that manage the developments of the lower mandible and decide the situation of mandibular condyle in the articulatory structures amid exercise and very still. In this way impediment stays just a solitary one of the predisposing factors in the etiology of TMD. ${ }^{[7]}$

\section{Conclusion}

We can conclude from our result that that in the TMJ, occlusal disharmonies were significantly related. Results may be specific to the population mentioned in the paper and will differ depending on the methods used. Further study on the subject is needed for an improved outcome. Thusly, the recommendation for this study are:

$\checkmark$ Further study with larger sample size is necessary.

$\checkmark$ The study should be done over a longer period of time.

$\checkmark$ Specific radiograph and examinations should be performed precisely, technician should have proper training, and the study should have a specialist on the field specific totemporomadibular joint (TMJ) region.

\section{References}

1. Jeffrey P. Okeson, 2003, Management of Temporomandibular Disorders and Occlusion, 5th edition, Mosby Publisher. 
2. Major M. Ash, SigurdRamfjord. 1995. Occlusion. 4th edition, W.B Saunders Company.

3. M. M. Alsawaf, D.A.Garlapo: Influence of tooth contact on the path of condylar movements, The Journal of Prosthetic Dentistry. 67:394-400,1992

4. Mike Torsten John, Henning Frank, Frank Lobbezoo, Mark Drangsholt, Karl Ernst Dette: No association between incisal tooth wear and temporomandibular disorders, The Journal of Prosthetic Dentistry. 87:197-203,2002

5. N. Okano, K.Baba, S. Akishige, T. Ohyama: The influence of altered occlusal guidance on condylar displacement, Journal of Oral Rehabilitation. 29:10911098, 2002

6. Philip H. Levy: A form and function concept of occlusion and the maxillomandibular relationship, J. Prosthet. Dent. 33: 149-157, 1975.

7. Dzingutè A, Pileičikienè $G$, Baltrušaityte A, Skirbutis G. Evaluation of the relationship between the occlusion parameters and symptoms of the temporomandibular joint disorder. Acta Med Litu. 2017;24(3):167-175. doi:10.6001/actamedica.v24i3.3551. 